\title{
HYBRID ACCOUNTS OF ETHICAL THOUGHT AND TALK
}

forthcoming in Routledge Handbook of Metaethics, edited by Tristram McPherson and David Plunkett

Teemu Toppinen

Some parts of language and thought plausibly mix the doxastic with the attitudinal. An effective example of this is provided by racial or ethnic slurs, such as 'roundhead', 'China Swede', or 'dumb Finn' - derisive terms used for the (allegedly) clannish, heavy drinking, knife-fighting, radicalism-tending, trouble-breeding Finnish immigrants in Minnesota and Michigan (or thereabouts) in early 1900s. Let us consider the following sentence:

S1 The strike was organized by roundheads.

When someone in, say, Minnesota, back then, used S1, she expressed her belief that the strike was organized by Finns, but she did more than this. She also somehow conveyed, at the same time, a derisive attitude toward Finns.

Another example of an area of discourse and thought that plausibly somehow blends the doxastic and the attitudinal is provided by ethical (or more broadly normative) talk and thought - that is, talk and thought concerning, roughly, what is good or bad, or right or wrong, or what there is reason to do. Ethical thought has both belief- and desire-like features. On one hand, our ethical views (about the wrongness of eating factory-farmed meat or catcalling, for example) are naturally characterized as beliefs, and occasionally also as correct or true; they figure in (sometimes valid) inferences that we draw, and so on. On the other hand, our ethical views are intimately tied to motivation and action: it is hard to make good sense of someone both as thinking that catcalling is wrong, and at the same time as engaging in catcalling. Ethical talk seems similarly dual-natured: on one hand, a use of 'Eating factory-farmed meat is wrong' seems to describe eating factory farmed meat as being a certain way; on the other hand, an utterance of this sentence also seems to express an opposing stance toward eating factory-farmed meat.

A significant part of metaethics, or metanormative theory, can be seen as the project of trying to make sense of this duality in ethical thought and talk.

Many accept a view that might be called cognitivism. On this view, the meaning of ethical claims, as well as the nature of moral thought, is to be explained by what they are about, or in terms of their representational content - with reference to the normative ways the world is, or with reference to the ways in which we cognitively access the normative properties and facts. For example, consider the claim that catcalling is wrong. According to a cognitivist view, the meaning of this claim will be explained, roughly, by (what determines) its truth-conditions, and the nature of a corresponding thought is explained in terms of representing catcalling as having a certain property. Whereas cognitivists seem to have easy time explaining the 'belief-like' or 'descriptive' features of normative thought and talk, accounting for the 'desire-like' and 'expressive' features is trickier for them. 
Some reject cognitivism, and accept instead a view that is sometimes called pure expressivism. On this view, the meaning of (some) ethical claims can be satisfactorily explained with reference to the purely non-representational, 'desire-like' or sentimental states of mind that they express. Likewise, on this view, to think an ethical thought just is to be in a non-representational state of the relevant sort. Pure expressivism captures the desire-like and expressive features of ethical thought and talk neatly, but faces challenges with respect to accounting for the belief-like and descriptive phenomena.

A recently popular option (with a potentially long history - see, e.g., Ross 1939: 255, Stevenson 1944) has been to go impure. One might suggest, first, that (i) ethical claims conventionally express both representational beliefs and desire-like states, or states that are constituted or realized by both representational beliefs and desire-like states. Second, one might also hold that (ii) to think an ethical thought is to be in a state that is constituted by both beliefs and desire-like states. Views that incorporate one or both of (i) and (ii) are often called bybrid views. Some of the hybrid views appeal to analogies with the way that slurs such as 'roundhead' work. Others develop the vague basic idea of appealing to both desire-like states and representational beliefs in accounting for normative thought and talk in different ways.

Within hybrid views, we may distinguish between bybrid cognitivism and hybrid expressivism. The former is a cognitivist view. That is, on this view, the conventional meaning of sentences such as 'Eating factory-farmed meat is wrong' is explained, at least in part, by their representational content. Also, according to this view, when someone thinks that eating factory-farmed meat is wrong (say), this is, at least in part, a matter of her having a belief (I sometimes omit the qualification 'representational' from this on), where this belief ascribes to eating factory-farmed meat the property of being wrong (or, anyway, a property such that the judgment is true just in case eating factory-farmed meat really has it). However, according to bybrid cognitivism, this is not all that there is to the meaning and nature of ethical talk and thought. Rather, there is also a desire-like element to the story. Hybrid expressivism, by contrast, involves rejection of cognitivism. That is, on this view, ethical sentences have no representational ethical content, and their meaning is to be explained, rather, in terms of the kinds of states that they conventionally express. However, according to bybrid forms of expressivism, representational beliefs still have a role to play in the explanation, as the states expressed by ethical sentences are partly constituted by representational beliefs. Both in the case of pure and hybrid expressivism, 'explaining' the meaning of normative sentences in terms of the states that they express can be taken to amount to giving a 'psychologistic' semantics for ethical language (cf. Schroeder 2010), or to giving a metasemantic theory, which might be compatible with, for example, a truth-conditional semantics (see Ridge 2014, Chrisman 2016).

In this chapter, I offer an overview of hybrid views, starting with the cognitivist ones. I shall not be able to properly discuss all the different kinds of hybrid cognitivist views that have been proposed in the literature. I'll focus on views that seek inspiration from the way that slurs work - on views defended by David Copp $(2001,2009,2014)$ and Daniel Boisvert (2008), in particular. Clearly this does not exhaust 
the important work on developing hybrid cognitivist or broadly similar views (see, e.g., Barker 2000; Tresan 2006; Bar-On \& Chrisman 2009).

\section{Motivations for hybrid cognitivism: internalism}

Why would a cognitivist go hybrid? The hope would be to capture the idea that there is something more to ethical talk and thought than describing and representing. Ethical language is used to endorse and to oppose; moral thought seems to be closely connected to motivation as well as to our emotional lives. Often the hope is to be able to capture, or at least to explain the allure of, some of the following (or some relevantly similar) 'internalist' theses (see Björklund et al. 2011):

(MOTIVATIONAL INTERNALiSM) Necessarily, if someone, $S$, thinks that she [morally] ought to $\varphi$, then, if she is rational, she is motivated to $\varphi$. (e.g., Smith 1994: ch. 3, Ridge 2014: ch. 2.)

(COMMUNAL INTERNALISM) Necessarily, if someone, $S$, thinks that she [morally] ought to $\varphi$, then, if she is rational, she is motivated to $\varphi$, or she is suitably related to some others, who, if rational, are motivated to act in accordance with their ought-thoughts. (cf. Blackburn 1998.)

(DisCOURSE INTERNALISM) Necessarily, if someone, $S$, asserts that she [morally] ought to $\varphi$, this is sufficient though defeasible evidence, independently of any other information concerning $S$ 's desire-like states, that $S$ is motivated to $\varphi$. (Cf. Copp 2001: 38, Finlay 2014: 135.)

These theses are quite plausible. Let us imagine planet Amorality (see Lenman 1999), on which no one is, and has never been, disposed to perform the actions to which they apply the word 'right', to refrain from performing the actions to which they apply the word 'wrong', and so on. Moreover, the inhabitants of the planet seem entirely rational (in the sense of being internally coherent). If communal internalism were false, there might be no obstacle to our taking the inhabitants of planet Amorality to be making genuine moral judgments. But it is really implausible to think that they would be doing so. Discourse internalism also seems attractive. We are reluctant to translate 'right' and 'wrong', as used on planet Amorality, as meaning right and wrong. But if discourse internalism were false, it would not be clear why. Motivational internalism is a more controversial thesis, at least if it is read as a claim about judgments concerning moral oughts. However, given a modestly 'rationalist' thesis, according to which a belief about what morally ought to be done is a belief about how reasons of a certain type shape up, it is quite plausible that a rational moral believer will have some motivation to act in accordance with her moral ought thought. In any case, whatever the plausibility of these internalist claims, they provide much of the motivation for 
developing hybrid cognitivist views. (For non-hybrid cognitivist attempts at capturing certain forms of internalism see, e.g., Smith 1994, Wedgwood 2007, and Schroeter \& Schroeter 2014.)

\section{Ethical talk: slurs, conventional implicatures, and discourse internalism}

Let us consider the following sentences:

S1 The strike was organized by roundheads.

S2 The strike was organized by Finns.

Plausibly, S1 says what S2 says - that the strike was organized by Finns. However, as noted above, someone who uses S1 is not just expressing this belief, but also, at the same time, somehow conveying a negative take on Finns.

Slur terms and other pejoratives have recently attracted a lot of attention from linguists and philosophers. There is much disagreement about how their workings should be understood - for instance, about the nature of the 'negative take' that they carry, and about whether they carry it as part of their content, or as a matter of pragmatics (see, e.g., Copp 2001, Hom 2008, Camp 2013, Bolinger forthcoming).

One possibility is that a use of a slur conventionally implicates certain attitudes. Conventional implicatures are carried by sentences in virtue of their conventional meaning, but do not contribute to their truth-conditional content (Grice 1989: 25-26, Potts 2007). (For instance, if I say that S1 is not true, I only seem to be denying that the strike was organized by Finns.) Another common example of conventional implicature is offered by the word 'but':

S3 Finns are good laborers, but troublemakers.

S4 Finns are good laborers and troublemakers.

Again, the truth-conditions of S3 plausibly are the same as those of S4. But the use of S3 also indicates that the speaker thinks that there is a contrast between being a good laborer and being a troublemaker.

Some hybrid cognitivists have proposed that ethical terms function roughly as slurs do, and that both could be understood in terms of conventional implicatures (Copp 2001, 2009, 2014; Boisvert 2008). Let us suppose that Ida accepts the following sentence:

Exploiting miners is wrong.

On Copp's view, when Ida says this, she ascribes to exploiting miners the property of being wrong - that is: the property of failing to be in accord with the authoritative standards for warranted blame - and also conventionally implicates that her policy is to avoid and oppose acts that fail to be in accordance with 
such standards. Somewhat similarly, on Boisvert's view, when Ida uses S5, she ascribes a certain wrongmaking property, $F$, to exploiting miners, and also conventionally expresses an attitude of opposition, or disapproval, toward performing actions with this property.

Given that the expression of the relevant non-belief attitudes by moral utterances works via something like conventional implicature, the hybrid cognitivist would seem to be well positioned to capture the truth of discourse internalism. If uses of moral sentences express certain motivational states in virtue of the conventional meaning of moral sentences, an utterance of such sentence will provide defeasible evidence of the presence of a motivational state regardless of independent knowledge about the speakers' psychology.

\section{Ethical thought: judgment-individuating hybrid cognitivism and motivational internalism}

One might wish to capture discourse internalism without accommodating motivational internalism. On Copp's $(2001,2014)$ view, for instance, moral beliefs are just ordinary representational beliefs that bear no necessary or conceptual connection to motivation. If Ida says that exploiting miners is wrong, she thereby expresses disapproval of acting in the relevant way. But she may believe that exploiting miners is wrong without being in any way against doing so.

However, a hybrid cognitivist who treats the expression of desire-like states by moral utterances as a matter of the conventional meaning of moral terms could also accommodate the truth of motivational internalism. On Boisvert's view, for example, to think that exploiting miners is wrong is to (a) believe that exploiting miners has a certain wrong-making property, $F$, and to (b) be opposed to, or disapprove of, performing acts with this property. On this kind of view, it would make sense that if Ida thinks that exploiting miners is wrong, she will, if she is instrumentally rational, be motivated to oppose exploiting miners. Following Michael Ridge (2014: ch. 3), we may call views such as Boisvert's judgmentindividuating forms of hybrid cognitivism. (See also Bar-On \& Chrisman 2009: 154-155, Ridge 2014: ch. 3, Laskowski 2014, Schroeder 2014.)

Might a hybrid cognitivist view that rejects motivational internalism nevertheless help to explain why motivational internalism seems attractive - the thought being that it's easy enough to confuse the idea that ethical assertions express certain attitudes with the idea that ethical beliefs involve such attitudes (see Copp 2001: 38, 2014: 59)? This doesn't seem to work. Consider the following quartet of sentences:
S6 Ida is a roundhead.
S7 John believes that Ida is a roundhead.
S5 Exploiting miners is wrong.
S8 Ida believes that exploiting miners is wrong.

A use of S6 plausibly conventionally implicates that the speaker views Finns negatively. Still, there is no temptation to think that it would follow from S7 that John views Finns negatively. A use of S7 would 
normally seem to convey, instead, the speaker's negative attitude toward Finns (see, e.g., Schroeder 2010: 203-204). Let us assume, then, that S5 conventionally implicates that the speaker is opposed to exploiting miners. It is unclear why this should help to explain the temptation to think that it follows from S8 that Ida is opposed to exploiting miners (cf. Ridge 2014: 87-89; Schroeder 2014: 283).

\section{Challenges for hybrid cognitivism}

The idea that moral utterances conventionally express motivational attitudes along with representational beliefs faces a number of challenges, which at the very least importantly restrict the options available to a hybrid cognitivist.

Projection. First, let us consider the following sentences:

S5 Exploiting miners is wrong.

S6 Ida is a roundhead.

S9 If Ida is a roundhead, she is a feminist.

S10 If exploiting miners is wrong, the pastor will be mad.

The expression of derisive stance toward Finns, carried by the term 'roundhead', projects in that when an atomic sentence in which this term figures generates a commitment to this attitude, this commitment remains in place also in complex sentences where the regular entailments are cancelled (e.g, negations, conditionals). For example, an utterance of $\mathrm{S} 9$ conveys a derisive attitude toward Finns just as much as an utterance of $\mathrm{S} 6$ does. This kind of projection behavior is a feature of conventional implicatures, quite generally. By contrast, whereas S5 conveys opposition to exploiting miners, any such opposition is cancelled in S10 (Strandberg 2012: 95). This generates a puzzle for the idea that moral utterances would convey attitudes via conventional implicatures.

However, according to the kinds of views considered above, utterances concerning wrongness, for instance, express opposition to any action, quite generally, insofar it is wrong. Given that this is so, a hybrid cognitivist could say that even though S10 does not express opposition to exploiting miners, it does express opposition to actions insofar as they are wrong. Slurs and ethical terms would then work similarly in this respect (Boisvert 2008: 185-186).

Cancellation. Another concern is that the expression of non-belief attitudes via moral utterance seems (to many) to be cancellable, whereas conventional implicatures generally are not. Consider the following pairs of sentences:

S11 The strike was organized by roundheads. Not that I have anything against Finns.

S12 Exploiting miners is wrong. Not that I have anything against wrongdoing. 
Many think that S11 is linguistically inappropriate in a sense in which S12 is not. If so, this is a strike against the conventional implicature view (Finlay 2005, Strandberg 2012, Fletcher 2014). By contrast, Copp $(2001,2009)$ suggests that the expression of attitudes by moral utterances is not cancellable without linguistic inappropriateness, and that this is a point in favor of his view.

It seems fair to say that when it comes to cancellation behavior, moral sentences differ from those containing slurs at least in that it is much more controversial what the right data is. A hybrid cognitivist who wishes to appeal to conventional implicatures, or to the analogy with slurs, should have some explanation for this.

Detachability. A third concern is that conventional implicatures are usually detachable. That is, there are alternative, 'neutral', ways of making the claims involving the expressions that carry conventional implicatures. This is clearly illustrated by sentence pairs such as S1 and S2, or S3 and S4. By contrast, there seem to be no neutral way of picking out, for example, the actions that are morally wrong. In response, one could note that hybrid cognitivists need not hold that the analogy with slurs holds in every respect. Also, it may be that some other pejoratives, such as 'asshole', offer a more promising analogy in this respect (Hay 2011).

Big Hypothesis. The fourth and final concern (to be discussed here) applies to judgmentindividuating forms of hybrid cognitivism, according to which, if "Exploiting miners is wrong" expresses a certain belief plus a state of opposition, then "Ida believes that exploiting miners is wrong" ascribes to Ida both this belief and this state of opposition. Schroeder (2009: 301) calls this the 'Big Hypothesis' - the name being due to the fact that, as was noted above, slurs, for instance, do not seem to obey this kind of hypothesis. Again, some other terms seem to provide a more helpful analogy:

S13 John thinks that Finns are good laborers, but troublemakers.

On Schroeder's (2010: 204) view, sentences such as S13 illustrate "that when 'but' appears inside a verb like 'thinks that', the speaker is not committed to the contrast, but rather saying that [John] thinks that there is a contrast". In many other contexts, 'but' seems to work like slurs do (e.g., projection behavior when it comes to negations and conditionals), and so it would seem like a promising model for a hybrid cognitivist.

Schroeder (2014) raises an interesting worry, though. Let us consider arguments of the following form:

S14 Everything John thinks is true.

S13 John thinks that Finns are good laborers, but troublemakers.

S3 Finns are good laborers, but troublemakers.

S15 Everything Ida believes is true. 
Someone who accepts S15 and S8 should also accept S5 (or reject one of the premises). In order to accept S5, she must, according to the judgment-individuating view, be opposed to wrongful actions. But where does the pressure to have this attitude come from? Plausibly, one may accept S15 without being opposed to wrongful actions. If so, the hybrid cognitivist should hold that accepting S8 involves being opposed to wrongful actions. Now, if this is right, then the hybrid cognitivist should think that 'wrong' works, in this respect, like 'roundhead' does. But we have also seen, in this section, that she should think that 'wrong' works like 'but' does. So, perhaps a hybrid cognitivist should hold that 'wrong' works like 'roundhead' in that $\mathrm{S} 8$ expresses opposition to wrongful actions, but also like 'but' in that $\mathrm{S} 8$ also ascribes this kind of opposition to Ida. Schroeder's worry is this: S13 ascribes a belief in contrast to John, but does not express the speaker's belief in the relevant contrast. But according to the current hybrid proposal, ethical terms cannot work in this way, because we can come up with an argument of the form illustrated by the one from S15 and S8 to S5 for any relevant term. This leaves us with an explanatory challenge. Given that a belief in contrast may be expressed by a term ('but') without being expressed by belief ascriptions using the relevant term (e.g., S13), why is it that the expression of non-belief attitudes by ethical terms is bound to project also through belief ascriptions?

\section{Conversational implicatures?}

Let us consider the following exchange between Ida and another roundhead (it seems that I, as a Finn, can get away with using this term):

Ida: "How is Reino adjusting to his work in the mines?"

Elis: "Well, he hasn't been to prison yet."

Ida: "Just how bad is it?"

Elis: "It sure is pretty cold in Minnesota this time of the year!"

What Elis first says is that Reino has not been to prison, yet (this exhausts the truth-conditional content of her statement), but what he means by saying this is something different. Plausibly, he means to suggest that Reino has not adjusted very well. Elis does not say this, but he implies as much. Elis's second statement concerns the temperature in Minnesota at a certain time, but what he conversationally implicates, using this sentence, is that he desires to avoid further discussion of Reino and his work in the mines.

Conversational implicatures are generated when we put together the conventional meanings of our sentences with our (implicit) knowledge concerning our conversational aims and effective means of achieving them. Very roughly, our assumption is that when someone engages in speech, she is sensibly pursuing her (usually cooperative) conversational goals. This standardly requires, for instance, being 
sincere, and making our contributions to discussion sufficiently (but not overly) informative and relevant to the topic at hand. In the above example, Elis openly flouts the maxim of relevance, and this allows Ida (and us) to infer, given that Elis is pursuing his and Ida's conversational ends in a cooperative way, that Elis believes that Reino has not adjusted very well, and that Elis does not want to discuss the topic in question. It is only by making these assumptions that we can make sense of Elis' contributions to the conversation as being in the service of what conversational goals we assume Elis has. Thus the conversational implicatures (Grice 1989).

Appealing to the phenomenon of conversational implicature (or some similar pragmatic mechanism), a cognitivist might suggest that there is no need for her to go hybrid, really. Rather, the idea would be, the practicality of normative language (which I have tried to encapsulate in the thesis of discourse internalism), and the temptations to accept motivational internalism, can be wholly explained by the purposes for which we use purely descriptive normative language (see, e.g., Milo 1981; Finlay 2005, 2014; Strandberg 2011, 2012; Fletcher 2014; Woods 2014). Views that combine cognitivism with this kind of pragmatic account of the practicality of moral language are sometimes taken to represent a brand of hybrid accounts, but given that this strategy is available for pretty much every cognitivist, it seems better to think of it as an attempt to explain how cognitivists can capture the relevant phenomena without going hybrid.

How might this kind of story work? A conversational implicature only arises when the audience is in a position to infer, given the supposed conversational aims of the speaker, that the speaker must believe what is being implicated. Conversational implicatures are calculable. So, when someone asserts S5 ("Exploiting miners is wrong"), for example, how do we calculate that the speaker (believes that she) is opposed to exploiting miners? Caj Strandberg's $(2011,2012)$ suggestion is, very roughly, as follows: the (mutually accepted) purpose of moral talk is, in part, to influence behavior. Someone should not, then, use S5 in case she is not opposed to exploiting miners. And so, given that she utters S5, and that she knows what she is opposed to, we are entitled to infer that she is opposed to exploiting miners.

Strandberg proposes that moral utterances convey that the speakers have certain motivational attitudes as a matter of generalized conversational implicature. Generalized conversational implicatures are conversational implicatures that arise regardless of the specifics of the context of utterance, unless they are somehow defeated (Grice 1989: ch. 2). For example:

S16 She will be here on Tuesday or on Wednesday.

S17 She drank some of the beer.

Someone who uses S16 thereby implicates that the person she is talking about won't be at the relevant location both on Tuesday and on Wednesday; someone who uses S17 thereby implicates that the person she is talking about did not drink all of the beer. Plausibly, these are just conversational implicatures, 
which need to be calculable, in principle, but the relevant implicatures arise standardly, without any further knowledge of the specific context in which these sentences are uttered.

Some suggest that the behavior of conversational implicatures nicely fits the way that moral utterances convey our attitudes. As explained above, conventional implicatures project and are neither cancellable nor detachable, while the expression of attitudes by moral utterances works differently in these respects, or at least does not clearly match the behavior of conventional implicatures. Conversational implicatures may fit the relevant data somewhat more smoothly, as conversational implicatures are not detachable, do not standardly project, and are easier to cancel without a residual feeling of linguistic inappropriateness (Strandberg 2012, Fletcher 2014).

However, conversational implicatures do not seem to provide a cognitivist with any very significant benefits. Appealing to conversational implicatures does not help the cognitivist to capture motivational internalism of any kind, including communal internalism. Neither does it seem to offer a debunking explanation for acceptance of motivational internalism. For instance, we are not tempted to think, on reflection, that someone who says 'Ida ate some of the cookies' must believe that Ida didn't eat all the cookies (see Tresan MS).

Appealing to conversational implicatures does not, then, seem sufficient for any old cognitivist in order to capture the kinds of phenomena that motivate cognitivists to adopt hybrid accounts. This is not to say that appealing to conversational norms, only, might not be sufficient in connection with some cognitivist views. For example, Stephen Finlay's $(2005,2014)$ end-relational view, on which ethical claims concern the ways in which certain ends of ours may be satisfied, might, when combined with suitable pragmatic explanations, allow us to better capture what's plausible in internalism.

\section{Hybrid expressivism}

According to pure expressivists, some ethical thinking consists solely in having certain desire-like attitudes (Blackburn 1998, Gibbard 2003). According to hybrid expressivism, all ethical thinking consists in having desire-like attitudes as well as suitably related beliefs. However, even a pure expressivist may hold that judgments deploying 'thick' terms such as (perhaps) 'courageous', or 'distributively unjust', involve representational beliefs. So, we could relativize views such as pure and hybrid forms of cognitivism and expressivism, more carefully, to different types of ethical claims, and say that one can be a pure expressivist about 'ought' or 'good' (say), but a hybrid expressivist about (for example) 'courageous'. Perhaps one could also combine an expressivist view about the thin with hybrid cognitivism about the thick (cf. Ridge 2014: ch. 8). However, in the following sections we're concerned with views that are hybrid expressivist with regard to the thin - that is, regarding judgments about oughts, goodness, wrongness, and so on.

It is helpful to introduce hybrid expressivism via ecumenical expressivism, a view advanced by Ridge $(2006,2007)$ in some of his earlier papers. On a somewhat simplified, 'plain vanilla' version of this view, S5 ("Exploiting miners is wrong"), for instance, would express, roughly, disapproval of actions insofar as 
they have some property, F, as well as a belief that exploiting miners has this property. Thus far this sounds very much like the judgment-individuating hybrid cognitivist view, discussed above. However, on Ridge's view, sentences such as S5 are not to be understood as being about a certain specific property across different speakers. Rather, what the relevant property, $F$, is, is determined by the desire-like states of the speaker, and varies from one speaker to another. For Ida, being $F$ might be a matter of being advised against by someone with character traits, $C$; for Elis, being $F$ might amount to failing to maximize happiness. (The relevant property might also be massively disjunctive.) Moreover, the idea is not that when Elis uses S5, the content of his claim is that exploiting miners fails to maximize happiness. Even though his utterance of S5 does, on Ridge's (early) view, express a belief that exploiting miners fails to maximize happiness, the content of this belief is not the representational content of his assertion, and one might sensibly think that while the belief expressed is true, the utterance isn't. (For roughly similar views, see Jackson 1999, Lenman 2003, Eriksson 2009.)

A subtly but importantly different kind of view, relational expressivism, rejects the idea that S5 expresses a certain desire, as well as a belief the content of which is determined by that desire. According to relational expressivism, S5 expresses, instead, a relational state - a state of having one's desire-like states and beliefs related in certain ways (Schroeder 2013, Toppinen 2013, Ridge 2014). One version of this view would say that S5 expresses a state of having one's desire-like states and beliefs related just as Elis' disapproval of failing to maximize happiness and his belief that exploiting miners fails to maximize happiness are related. We could also put the idea as follows: S5 expresses a certain kind of higher-order state, that is, a state of being in a certain kind of hybrid state - a higher-order state that is massively multiply realizable by hybrid states roughly like the ones that Ridge's earlier view suggested would be expressed by ethical sentences (Toppinen 2013). If Ida is against actions that go against the advice of someone with character traits $C$, and believes that exploiting miners goes against such advice, and Elis is against failing to maximize happiness and believes that exploiting miners fails in this respect, then Ida and Elis both are, despite the differences in the contents of their respective states of opposition and belief, in a relational higher-order state of this kind.

Ridge's (2014) more recent view (still called 'ecumenical expressivism') is the most sophisticated development of relational expressivism to date. On this view, all ethical claims concern the relation of actions, etc., to acceptable standards for practical reasoning. The state expressed by S5 (for example) would be a relational state that consists of (a) a 'normative perspective' and (b) a suitably related belief. Normative perspectives are understood roughly in terms of plans and policies that rule out certain standards. The belief-component of a state realizing the relational state expressed by S5 would then be, very roughly, a belief that exploiting miners is ruled out by the standards not ruled out by the thinker's normative perspective - a belief that exploiting miners is ruled out by the admissible standards, for short (to use a technical term of Ridge's). Similarly, thinking that promoting women's suffrage is good would involve having a normative perspective plus a belief that promoting women's suffrage scores high on any of the admissible standards, and so on. 


\section{Some potential advantages of hybrid expressivism}

Frege-Geach and wishful thinking. Why would an expressivist go hybrid? Here is a nice set of challenges for any expressivist: explain how the meanings of complex ethical sentences (e.g., S10, "If exploiting miners is wrong, the pastor will be mad") are determined by the meanings of the simpler sentences (e.g., S5) they are made up of, and do this in a way that allows us to explain why, for example, someone who accepts S5 and S10 would be inconsistent if she went on to accept S18, and why she rationally should accept S19 (or reject one of S5 and S10).

S18 The pastor won't be mad.

S19 The pastor will be mad.

This is, on one understanding, the so-called Frege-Geach problem for expressivists (Schroeder 2010: 4154, 105-112). A related challenge is that of explaining why moving from a justified belief in S10, via simply coming to be in the desire-like state expressed by S5, to a descriptive, representational belief in S19 does not instantiate wishful thinking (Dorr 2002).

A number of responses to these problems have been proposed on behalf of the pure expressivist, but it's controversial whether these responses succeed. Plausibly, a solution to the Frege-Geach problem should provide us with a recipe for determining what the complex sentences express as a function of what their parts express (Schroeder 2010: 48-54). The recipe offered by hybrid expressivism is quite simple. Consider, again, the following argument:

S10 If exploiting miners is wrong, the pastor will be mad.

S5 Exploiting miners is wrong.

S19 The pastor will be mad.

According to hybrid expressivism, my acceptance of S5 is a matter of my being in a state that is realized by a desire-like state (e.g., a normative perspective á la Ridge) and a suitably related belief, let's say a belief that lying is $F$ (e.g., such that it is ruled out by standards with some property, $G$ ). My acceptance of S10 will then involve, again, the same desire-like state, as well as a belief that if lying is $F$, then the pastor will be mad. Any ethical sentence will express a state realized by a certain desire-like state and a belief, the content of which we get by substituting for 'wrong', in the original sentence, the name of the corresponding wholly descriptive property (e.g., being ruled out by the admissible standards). This gives us the recipe for determining what is expressed by the complex sentences.

We can now explain why acceptance of S10 and S5 together with rejecting S19 is inconsistent (Ridge 2006, 2014: ch. 5; Toppinen 2013). This would involve having the beliefs that if lying is $F$, the pastor will be mad, that lying is $F$, and that it is not the case that the pastor will be mad - which is 
inconsistent. Moreover, Ridge (2014: ch. 5.5) proposes, acceptance of S10 and S5 together with rejecting S19 is logically inconsistent, because it involves inconsistency in belief "on any acceptable substitution of the non-logical terms of the argument". Similarly, we should now be in a position to explain why someone who accepts S10 and S5 is rationally committed to accepting S19 (or rejecting one of the premises): the beliefs involved in accepting S10 and S5 commit one to the belief involved in accepting S19. This also allows the hybrid expressivist to escape the worry from wishful thinking. According to the hybrid expressivist view, acceptance of S19 by someone, on the basis of S10 and S5, will always be based on the beliefs involved in accepting S10 and S5.

Many attitudes. There are a number of 'propositional attitudes' other than beliefs. For some proposition, $p$, we may believe that $p$, but we may also desire that $p$, hope that $p$, wonder whether $p$, and so on. This applies also to normative propositions. Just as one may believe (at least in a suitably minimalist sense) that exploiting miners is wrong, one may also desire or hope that exploiting miners is wrong. Expressivists cannot simply explain these attitudes as different attitudes that all are about exploiting miners being wrong. Even if they do have a story about what it is to believe that exploiting miners is wrong, they would also seem to owe us an account of what it is to hope that exploiting miners is wrong, and so on. Mark Schroeder (2010: 84) calls this the Many attitudes problem. Hybrid expressivism offers promising resources here. The idea would be that to hope that exploiting miners is wrong is to be in a state of having some suitable desire-like state in relation to a certain property as well as a state of hoping that exploiting miners has that property. The idea generalizes in obvious ways (Ridge 2014: ch. 5).

Akrasia. Expressivists also plausibly need to make sense of the possibility of akrasia - roughly: of the possibility of thinking that one ought to perform some action while having no plan or intention to act accordingly. This seems impossible if one identifies thinking that one ought to perform an action with having a plan to perform this action (Gibbard 2003). Ridge (2007) suggests that a hybrid view, according to which the desire-like element in a normative judgment is directed at actions with certain properties, quite generally, makes room for akrasia, even assuming that the relevant desire-like states are plan-like commitments. An agent might think that one ought to refrain from murder - that is, roughly: plan to maximize happiness, and believe that murder fails to maximize happiness - and yet, irrationally, fail to form an intention to refrain from murdering in her particular circumstances.

Uncertainty. Expressivists also have trouble making acceptable sense of ethical uncertainty. We may think that $x$ is really good, whereas $y$ is only moderately good (call this importance), but be much more certain about $y$ being moderately good than we are about $x$ being really good (call this confidence). If normative judgments are just desire-like states, it's hard to see how we can make sense of this. We might appeal to the strength of desires in accounting for importance, or perhaps in accounting for confidence, but we cannot explain both importance and confidence with reference to the strength of desires (Smith 2002). Adopting a hybrid view might be of some help here. Roughly, we could suggest that the level of confidence in some normative judgment may always be explained with reference to the belief involved in making this judgment (Lenman 2003). It is by no means clear that this will work, but hybridism offers 
some extra resources for an expressivist also in this context (for discussion, see Bykvist \& Olson 2009; for a related challenge, see also Egan 2007, Ridge 2015b).

\section{Challenges for hybrid expressivism}

Expression. Let's suppose Elis is a hedonistic utilitarian. On the 'plain vanilla' version of Ridge's (2006, 2007) earlier view, Elis' utterance of S5 would express something like disapproval of failing to maximize happiness plus a belief that exploiting miners fails to maximize happiness. On this view, the state expressed by utterances of S5 varies from one speaker to another and is determined by what states the speaker is in. However, given that the state expressed is a function of the speaker's attitudes, it is difficult to see how Elis' utterance could express these particular states in virtue of S5's conventional meaning (Schroeder 2009).

Relational expressivism avoids this worry. According to this view, S5 may be conventionally associated with a certain relational or higher-order state (which may be differently realized in the case of different speakers). A use of this sentence may, for example, be evidence of the speaker being in such relational state, or be permissible only when the speaker is in such state - to briefly indicate two ways of understanding the expression relation (Toppinen 2013: sec. 4).

Disagreement. If Ida thinks that exploiting miners is wrong, and Elis thinks it's not, they disagree. Expressivists cannot explain this simply by saying that it cannot be true both that exploiting miners is wrong and that it isn't. Plausibly, their account of Ida's and Elis' disagreement should appeal to the idea that being in the states expressed by "Exploiting miners is wrong" and "Exploiting miners is not wrong" involves some relevant kind of incoherence. But now, suppose that Ida's judgment that exploiting miners is wrong is realized by her being against acting in ways that are not recommended by someone with character traits, $C$, and believing that exploiting miners would not be recommended by someone with character traits, $C$, whereas Elis' judgment that exploiting miners is not wrong is realized by Elis' being against failing to maximize happiness and believing that exploiting miners does not fail in this respect, under the relevant circumstances. It seems that being in these states does not secure incoherence of any relevant kind (Toppinen 2013: sec. 5, Eriksson 2015). That is, one could coherently be against actions that fail to maximize happiness as well as against actions that would not be recommended by someone with $C$, and one could, moreover, coherently believe both that exploiting miners would not be recommended by someone with $C$ and that it does not fail to maximize happiness.

Relational expressivism avoids this worry, too (Toppinen 2013: sec. 5). For suppose that we ask whether one can coherently be in the kinds of relational states that are realized, in Ida's and Elis' case, by their respective states of opposition and belief. Being in both of these relational states would involve opposing actions that have a certain property and believing both that exploiting miners has and doesn't have this property. This would clearly be inconsistent. This does not yet amount to giving a fully satisfying account of disagreement (Toppinen 2013: sec. 5). However, giving a fully satisfying account of 
disagreement would seem to be a problem for expressivism quite generally, and not for hybrid forms of expressivism, in particular (see, e.g., Dreier 2009, 2015; Ridge 2014: ch. 6, 2015a).

Ethical judgment ascriptions. The hybrid expressivist recipe for determining the states expressed by complex sentences doesn't work entirely generally. A couple of sentences:

S8 Ida believes that exploiting miners is wrong.

S21 If Kant is right, then exploiting miners is wrong.

S8 does not express a state of having some normative perspective as well as a belief that Ida believes that exploiting miners is ruled out by the standards that are admissible by the lights of that normative perspective. Rather, S8 would seem to concern the kind of normative perspective that Ida has. Similar concerns arise in relation to sentences such as S21 (Carr 2015, Ridge 2015a). And whatever story we give of the meaning of S8 (say), it should allow us to explain how one can validly derive from S8, together with the claim that what Ida believes is true, the conclusion that exploiting miners is wrong (Schroeder 2009, Ridge 2014: ch. 7).

Details about the relational state. There is of course a lot more to be said about how exactly we should understand the kinds of hybrid states that, according to hybrid expressivism, realize the relational states expressed by ethical sentences. Ridge (2014: ch. 4) suggests that we should understand the desirelike component (largely) negatively, as ruling out acceptance of certain kinds of standards. This way, he suggests, we can do justice to the idea that someone engaged in ethical thought may not accept any very specific set of standards. However, normative perspectives also have certain positive elements, on Ridge's view: policies, aspirations and propensities to act and deliberate in certain ways.

How should we, then, understand the beliefs that are relevantly related to these perspectives? One worry is that it's not plausible that these beliefs would present the relevant standards to us as our standards (Schafer 2015). However, a hybrid expressivist may reject the idea that the relevant beliefs concern our own standards (under that description). Rather, the idea is that these beliefs concern certain standards that are salient to us thanks to our having a certain kind of normative perspective. Ridge (2015a: 475) offers as an analogy a case of someone who hears a tune and says that he doesn't like songs 'like that one' - where this someone may not be able to say what the relevant similarity is between the tunes that he thereby groups together.

Even if hybrid expressivism offers resources for dealing with some of the hard problems for expressivists, it remains to be seen how it deals with the rest. Some of the worries raised above are yet to be answered. Also, expressivists of any stripe have yet to offer a fully satisfying account of, for example, disagreement and ethical uncertainty. There's also more to be said about how to capture just the sorts of internalist theses that should be captured, about how the different expressivist views generalize to normative or evaluative thought and talk outside the realm of the (broadly) ethical, and so on. But of 
course all the metaethical options on the table are work in progress. Just as with cognitivism, with expressivism, too, the most plausible ways of going hybrid seem to hold considerable promise.

ACKNOwLedgments: I thank Jamie Fritz, Tristram McPherson, David Plunkett, and Pekka Väyrynen for helpful comments.

\section{WORD COUNT: 8286}

(SOME) RELATED TOPICS: Expressivism; Thick concepts; The Frege-Geach problem; The significance of ethical disagreement for theories of ethical thought/talk; Cognitivism and non-cognitivism; Ethical judgment and motivation; Metasemantics and metaethics; Quasi-realism

\section{REFERENCES}

Barker, S., 2000, "Is Value Content a Component of Conventional Implicature," Analysis 60: 268-279.

Bar-On, D. \& Chrisman, M., 2009, "Ethical Neo-Expressivism," in R. Shafer-Landau (ed.): Oxford Studies in Metaethics, Volume 4 (Oxford: Oxford University Press).

Björklund, F., G. Björnsson, J. Eriksson, R. Francén Olinder \& C. Strandberg, 2011, "Recent Work on Motivational Internalism," Analysis 72: 124-137.

Blackburn, S., 1998, Ruling Passions (Oxford: Oxford University Press).

Boisvert, D., 2008, “Expressive-Assertivism,” Pacific Pbilosophical Quarterly 89: 169-203.

Bolinger, R. J., forthcoming, “The Pragmatics of Slurs,” Noûs.

Bykvist, K. \& Olson, J., 2009, “Expressivism and Moral Certitude,” Pbilosopbical Quarterly 59: 202-215.

Camp, E., 2013, "Slurring Perspectives," Analytic Pbilosopby 54: 330-349.

Chrisman, M., 2016, The Meaning of 'Ought' (Oxford: Oxford University Press).

Carr, J., 2015, "Ecumenical Expressivism Ecumenicized," Analysis 75: 442-450.

Copp, D., 2001, "Realist-Expressivism: A Neglected Option for Moral Realism," in E. F. Paul, F. D. Miller, Jr. \& J. Paul (eds.): Moral Knowledge (New York: Cambridge University Press).

Copp, D., 2009, "Realist-Expressivism and Conventional Implicature," in R. Shafer-Landau (ed.): Oxford Studies in Metaethics, Volume 4 (Oxford: Oxford University Press).

Copp, D., 2014, "Can a Hybrid Theory Have It Both Ways? Moral Thought, Open Questions, and Moral Motivation," in G. Fletcher \& M. Ridge (eds.): Having It Both Ways (New York: Oxford University Press).

Dorr, C., 2002, "Non-cognitivism and Wishful Thinking,” Nôus 36: 97-103.

Dreier, J., 2009, "Relativism (and Expressivism) and the Problem of Disagreement," Pbilosophical Perspectives 23: 79_ 110.

Dreier, J., 2015, "Truth and Disagreement in Impassioned Belief," Analysis 75: 450-459.

Egan, A., 2007, "Quasi-Realism and Fundamental Moral Error," Australasian Journal of Philosophy 85: 205-219.

Eriksson, J., 2009, “Homage to Hare: Ecumenism and the Frege-Geach Problem,” Ethics 120: 8-35.

Eriksson, J., 2015, "Explaining Disagreement: A Problem for (Some) Hybrid Expressivists," Pacific Pbilosopbical Quarterly 96: 39-53.

Finlay, S., 2005, "Value and Implicature," Pbilosopher's Imprint 5 (4): 1-20. 
Finlay, S., 2014, Confusion of Tongues: A Theory of Normative Language (New York: Oxford University Press).

Fletcher, G., 2014, “Moral Utterances, Attitude Expression, and Implicature,” in G. Fletcher \& M. Ridge (eds.):

Having It Both Ways (New York: Oxford University Press).

Gibbard, A., 2003, Thinking How to Live (Cambridge, Mass.: Harvard University Press).

Grice, P., 1989, Studies in the Way of Words (Cambridge, Mass.: Harvard University Press).

Hay, R., 2013, "Hybrid Expressivism and the Analogy between Pejoratives and Moral Language," European Journal of Philosophy 21: 450-474.

Hom, C., 2008, “The Semantics of Racial Epithets,” Journal of Philosophy 105: 416-440.

Jackson, F., 1999, “Non-cognitivism, Validity and Conditionals," in D. Jamieson (ed.): Singer and His Critics (Oxford: Blackwell Publishers).

Laskowski, N., 2015, “Non-Analytical Naturalism and the Nature of Normative Thought: A Reply to Parfit,” Journal of Ethics and Social Philosophy (http://www.jesp.org/articles/download/nonanalytical-naturalism.pdf).

Lenman, J., 1999, “The Externalist and the Amoralist,” Pbilosopbia 27: 441-457.

Lenman, J., 2003, “Noncognitivism and the Dimensions of Evaluative Judgment,” BEARS (Brown Electronic Article Review Service (http://www.brown.edu/Departments/Philosophy/bears/).

Milo, R. D., 1981, “Moral Indifference,” Monist 64: 373-393.

Potts, C., 2007, "Into the Conventional-Implicature Dimension,” Philosophy Compass 2: 665-679.

Ridge, M., 2006, “Ecumenical Expressivism: Finessing Frege,” Ethics 116: 302-337.

Ridge, M., 2007, “Ecumenical Expressivism: The Best of Both Worlds?” in R. Shafer-Landau (ed.): Oxford Studies in Metaethics, Volume 2 (Oxford: Oxford University Press).

Ridge, M., 2014, Impassioned Belief (Oxford: Oxford University Press).

Ridge, M., 2015a, "Replies to Critics,” Analysis 75: 471-488.

Ridge, M., 2015b, “I Might Be Fundamentally Mistaken,” Journal of Ethics and Social Philosophy 9.

Ross, W. D., 1939, Foundations of Ethics (Oxford: Oxford University Press).

Schafer, K., 2015, “The Unity of Normative Judgement: On Ridge’s Impassioned Belief," Analysis 75: 442-450.

Schroeder, M., 2009, “Hybrid Expressivism: Virtues and Vices,” Ethics 119: 257-309.

Schroeder, M., 2010, Noncognitivism in Ethics (Abingdon: Routledge).

Schroeder, M., 2013, “Tempered Expressivism,” in R. Shafer-Landau (ed.): Oxford Studies in Metaethics, Volume 8 (Oxford: Oxford University Press).

Schroeder, M., 2014, "The Truth in Hybrid Semantics," in G. Fletcher \& M. Ridge (eds.): Having It Both Ways (New York: Oxford University Press).

Schroeter, L. \& F. Schroeter, 2014, "Why Go Hybrid? A Cognitivist Alternative to Hybrid Theories of Normative Judgment," in G. Fletcher \& M. Ridge (eds.): Having It Both Ways (New York: Oxford University Press).

Smith, M., 1994, The Moral Problem (Oxford: Blackwell Publishers).

Smith, M., 2002, "Evaluation, Uncertainty and Motivation," Ethical Theory and Moral Practice 5: 305-320.

Strandberg, C., 2011, “The Pragmatics of Moral Motivation,” Journal of Ethics 15: 341-369.

Strandberg, C., 2012, “A Dual Aspect Account of Moral Language,” Philosophy and Phenomenological Research 84: 87122.

Toppinen, T., 2013, "Believing in Expressivism," in R. Shafer-Landau (ed.): Oxford Studies in Metaethics, Volume 8 (Oxford: Oxford University Press).

Tresan, J., 2006, “De Dicto Internalist Cognitivism,” Nôus 40: 143-165. 
Tresan, J., MS, “Communal Internalism is the Real Deal: A Defense."

Woods, J., 2014, “Expressivism and Moore's Paradox,” Philosopher's Imprint 14, no. 5: 1-12.

Wedgwood, R., 2007, The Nature of Normativity (Oxford: Oxford University Press).

\section{FURTHER READING}

Fletcher, G. \& M. Ridge (eds.), 2014, Having It Both Ways (New York: Oxford University Press).

Schroeder, M., 2015, Expressing Our Attitudes: Explanation and Expression in Ethics, Volume 2 (Oxford: Oxford University Press). 